\title{
Comparison of Calculated Work Function of Metals Using Metallic Plasma Model with Stabilized Jellium, Ab-Initio Approach and Experimental Values
}

\author{
Olubosede O. \\ Department of Physics and Electronics Department \\ Adekunle Ajasin University Akungba-Akoko, Ondo State, Nigeria \\ Tel: 234-806-328-8349Ｅ-mail: sayolayo@yahoo.com \\ Afolabi O.M. \\ Department of Physics and Electronics Department \\ Adekunle Ajasin University Akungba-Akoko, Ondo State, Nigeria \\ Tel: 234-703-752-9390 E-mail: afolabi100@yahoo.com
}

Fayose R.S.

Department of Physics and Electronics Department

Adekunle Ajasin University Akungba-Akoko, Ondo State, Nigeria

Tel: 234-703-012-9407_E-mail: oluboy_2005@yahoo.com

\section{Oniya E.O.}

Department of Physics and Electronics Department Adekunle Ajasin University Akungba-Akoko, Ondo State, Nigeria

Tel: 234-803-503-3421Ｅ-mail: ebeno4ever@yahoo.com

Tomiwa A.C.

Department of Physics and Electronics Department

Adekunle Ajasin University Akungba-Akoko, Ondo State, Nigeria

Tel: 234-803-376-1169Ｅ-mail: tomiwa.akinyemi@yahoo.com

Received: January 28, 2011

doi:10.5539/apr.v3n2p171
Accepted: February 14, 2011 Published: November 1, 2011

URL: http://dx.doi.org/10.5539/apr.v3n2p171

\begin{abstract}
The work function of metals was calculated using the metallic plasma model (MPM). The results obtained were compared with the available results of the stabilized jellium model (SJM), $A b$-initio model and the experimental values. Result shows that the stabilized jellium model was in good agreement with experimental values for the simple metals, the transition, inner transition and rare-earth metals. The metallic plasma model gave results that are agreeable with experimental values for most of the metals especially the polycrystalline metals. The $a b$-initio results were higher than experimental values except for $\mathrm{Ba}, \mathrm{Ca}$ and $\mathrm{Sr}$, this shows that the metallic plasma model is more reliable in predicting the work function of metals.
\end{abstract}

Keywords: Metallic plasma model, Stabilized jellium model, Ab-initio model, Metallic surfaces, Work function, Electron density parameter 


\section{Introduction}

Work function $\left(W_{f}\right)$ is the minimum energy required to extract an electron from a crystal. It is essential in the determination of the physical and chemical properties of metallic surfaces. It is an intrinsic parameter which is affected by atomic arrangement in the metal and inter-atomic distances within the metal and very vital in understanding some surface phenomena such as the calculation of corrosion rates, properties of materials for light emitting and photosensitive devices (Halas, S. 2006, P. 951-968 and Michaelson H.B, 1977 P. 4729-4733). $W_{f}$ can be measured absolutely using thermionic emission, photoelectric emission and field emission. It can also be measured relatively using the retarding potential and vibrating capacitor methods (Hudson J.B, 1992, P. 250-305). Measurement of work function is improving with advancement in technology and development of better methods of measurement (Yoshitake M and Yoshitake K, 2006 P. 144 and Nishiyama H and Inoue Y, 2006 P. 2644-2659).

Much attention has been paid to the theoretical study of work function. The first theory proposed for the work function of metals and the self-consistent many-electron calculation of the work function of metals from first principles within the free electron model produced results that were not in good agreement with experimental values (Wigner E. and Bardeen, J. 1935, P. 84-87 and Smith, J.R. 1969, P. 522-529). Lang and Kohn (Lang, N.D and Kohn.W. 1971 P. 1215-1223) developed the theory of work function of metals based on the jellium model. In the jellium model, the ionic point charges are replaced by a semi-infinite distribution of constant positive charges. The work function of metals was calculated by solving the Kohn-Sham equation self-consistently using the kinetic, exchange, and correlation energies based on the local density approximation. The results were only in good agreement with experimental values for some simple metals (Lang N.D and Kohn.W. 1970, P. 4555-4567). Mahan and Schaich (Mahan, G.D and Schaich, W.L. 1974, P. 2647-2651) also derived another formula for calculating work function based on the jellium model, which is an improvement to the formula of Lang and Kohn. The formula showed that work function might be related to the ground state energy per electron of the bulk metal. Work functions of $\mathrm{Al}, \mathrm{Li}, \mathrm{Na}, \mathrm{Mg}, \mathrm{Pb}$, and $\mathrm{Zn}$ calculated using density functional theory of the inhomogeneous electron gas were not in good agreement with experimental values (Monnier R., Perdew, J.P., Langreth, D.C. and Wilkins, J.W. 1978, P. 656-66).

The stabilized jellium model (SJM) was developed by Perdew et al (Perdew, J.P., Tran, H.Q. and Smith, E.D. 1990 P.11627-11636). It evolved from the variational self-consistent method of the ground state properties of metals (Monnier R., Perdew, J.P., Langreth, D.C. and Wilkins, J.W. 1978, P. 656-66). The model has all the properties of the jellium model with an additional constant potential to the effective potential of the metal. Recently, Brodie (Brodie I 1995, P. 13660.) redefined the work function idea by reducing it to the work done by an electron against the image forces, expressing the work function in terms of the atomic radius, the Fermi energy and the effective mass of the electron.

In this work, a fundamental relationship between the work function, the Fermi energy and the electron density parameter is established taking the entire novel approach to the application of plasma physics concept. The results obtained were compared with the results obtained from other models like the pseudopotential (SJM), Ab-initio method as well as experimental values.

\section{Theoretical Consideration}

The work done against forces acting between an electron emerging from a metal surface and its image contributes significantly to the work function of the metal (Jackson J.D 1975, P. 179. For a planar conducting surface at zero potential, the work required to take an electron initially at a distance $d_{o}$ to infinity ( Halas, S, T.Durakiewicz 1998, P.10815-10826) is

$$
W_{\text {image }}=\frac{e^{2}}{16 \pi \varepsilon_{0} d_{0}}
$$

where $e$ is the electronic charge and $\varepsilon_{0}$ is the permittivity of free space.

The polarization length in a metal may be evaluated by replacing $\frac{1}{2} k T$ by $E_{F}$ in the classical formula for distance $d$, from plasma physics (Ibach, H. 1997, P. 193-263) by 


$$
d=\sqrt{\frac{2 \varepsilon_{0} E_{F}}{n e^{2}}}
$$

$n$ is the average density of free electrons in a metal lattice and e is the electronic charge.

Comparing the d-value with Thomas-Fermi screening length, equation 2 corresponds to Debye length in plasma physics (Kittel C. 1996, P. 235-236);

$$
D=\sqrt{\frac{2 \varepsilon_{0} E_{F}}{3 n e^{2}}}
$$

It can be seen that $D=d / \sqrt{3}$ hence the ion is completely screened at a distance somewhat larger than $d$ (Kittel C. 1996, P. 235-236). It should be emphasized that both the ion screening and the image forces appear due to the displacement of an electron from its average position. Therefore, we assume that when an electron is shifted from a remote plane (where, under normal conditions, the electron density tends to zero) by $d_{0}=\frac{d}{\alpha}$ where $\alpha$ is a factor of the order of unity and $d$ is given by equation (2), the ion is completely screened, whilst the image force are just starting to act.

By substituting $d_{0}=\frac{d}{\alpha}$ and rewriting the equation (1) we have:

$$
\varphi=\frac{1}{2} \frac{e^{2}}{8 \pi \varepsilon_{0} a_{0}} \frac{a_{0}}{d}=\frac{\alpha}{2} R y d /\left(\frac{d}{d_{0}}\right)
$$

0

where $a_{0}$ is the Bohr radius $(0.52918 A)$, the Rydberg is the atomic unit of energy ( $R y d=13.605 \mathrm{eV}$ ). The $d$-value is calculated using equation (2), in which the free-electron density $\mathrm{n}$, is replaced by the density parameter $r_{s}$ defined as follows (Ashcroft N.W and Mermin N.D 1976, P. 345-368)

$$
\frac{1}{n}=\frac{4}{3} \pi_{s}^{3}
$$

and Fermi Energy $E_{F}=\frac{1.84}{r_{s}^{2}}$ hartree.

Equation (2) can be rewritten as:

$$
d=\sqrt{\frac{2 \varepsilon_{o} E_{F} \frac{4}{3} \pi_{s}^{3}}{e^{2}}}=\sqrt{\frac{E_{F}}{\frac{1}{2}\left(e^{2} / 4 \pi \varepsilon_{o} a_{o}\right)} \frac{r_{s}^{3}}{3 a_{o}}}=\frac{a_{o}}{\sqrt{3}}\left(\frac{E_{F}}{R y d}\right)^{1 / 2}\left(\frac{r_{s}}{a_{o}}\right)^{3 / 2}
$$

Substituting equation (5) into equation (4) gives:

$$
\varphi=\frac{\alpha \sqrt{3}}{2} R y d\left(\frac{E_{F}}{R y d}\right)^{-1 / 2}\left(\frac{r_{s}}{a_{o}}\right)^{-3 / 2}
$$

The work function of elements in terms of Fermi energy $E_{F}$ and electron density parameter $r_{s}$ is expressed as. 


$$
\varphi / e V=\frac{11.78 \alpha}{r_{s}^{3 / 2}\left(E_{F} / \text { Ryd }\right)^{1 / 2}}=\frac{43.46 \alpha}{r_{s}^{3 / 2}\left(E_{F} / e V\right)^{1 / 2}}
$$

where $r_{s}$ is Bohr radii, $E_{F}$ is Fermi energy The scaling factor $\alpha$ which defines the fraction of the polarization length from which the integration of the image force should be done was assumed to be equal to unity ( Halas, $\mathrm{S}$, T.Durakiewicz 1998, P.10815-10826) for all elements except the alkali metals, Ca, Sr, Ba, Ra and Tl, for which it was assumed to be equal to 0.86 , the factor is treated as just an empirical constant. The equation (7) is the metallic plasma model (MPM) that was employed in this work to evaluate work function of metals.

\section{Results and Discussion}

The work function of metal that was calculated in this work using MPM was compared with those of SJM, $A b$-initio model and experimental values reported in other papers. These results are presented in Table 1. Figure 1 shows the comparison of the MPM results and experimental values with electron density parameter. The MPM obtained results are in excellent agreement with the experimental work function values for pure-metal polycrystalline surfaces. The agreement in the case of semiconductors $(\mathrm{Ge}, \mathrm{Si})$ is not as good as that of metals as the values are clearly too low. This may be due to the fact that the valence electrons in semiconductors are strongly localized as a result of covalent bonding of the atoms, thereby making the efficiency of the screening by the valence electron poor. However, for the alkali metals, $\mathrm{Ca}, \mathrm{Mg}, \mathrm{Sr}$ and $\mathrm{Ba}$, results fit fairly well with the experimental values.

For some metals, there are large departures from this relationship which could also be attributed to the complexity of their electronic structures. Figure 2 shows the Comparison of SJM and experimental Values with electron density parameter as seen from (Osiele, O.M. and Olubosede, O. 2007, P. 9-16.). SJM agrees well with metals in the low density limit but not too accurate in the high density limit. This limitation of SJM is well observed in the high-density limit, $r_{s} \leq 3.0 \mathrm{au}$ where the agreement with the experimental values decreases with decrease in the electron density parameter. This may be due to the fact that the simple metals are in the low-density limit. In addition, the properties of non-simple metals are affected by band structure and crystal structure, which the SJM does not put into consideration. However, SJM conformed with the experimental values in the low density region $r_{s} \geq 3.0 \mathrm{au}$. Figure 3 shows the comparison of Ab-initio method and experimental values with electron density parameter. In this derived figure, Ab-initio results were all higher than the experimental values except in $\mathrm{Ba} \mathrm{Ca}$ and $\mathrm{Sr}$. For all the methods, the calculated work function value reduces with an increase in electron density parameter.

\section{Conclusion}

The MPM used in this work is a new formula which shows the relationship of the work function, Fermi energy as well as the electron density parameter. In this paper, the MPM has been successfully compared with the SJM (Osiele, O.M. and Olubosede, O. 2007, P. 9-16.), Ab-initio (Ashcroft N.W and Mermin N.D 1976. P. 345-368) and Experimental values (Michaelson H.B, 1977 P. 4729-4733). The SJM proved to be more accurate for calculations of work function of simple metals, while MPM has agreeable results for pure-metals and polycrystalline surfaces. However, in the semiconductors (Ge and $\mathrm{Si}$ ) it gives a lower value due to low screening efficiency. The work function of elemental metals obtained from the SJM calculation was in fairly good agreement with experimental values. Considering the cubic arrangements of lattice structures, the SJM gave more accurate results for the work functions of body centred cubic (bcc) metals, followed by hexagonal closed packed (hcp) metals and was least accurate for face centred cubic (fcc) metals. This shows that the SJM could be used to calculate and predict the work function of metals. Although MPM and SJM were in good agreement with the experimental values, MPM was more accurate than SJM for non-simple metals. This may be due to the band structure, crystal strength and crystal structure which the SJM does not put into consideration.

\section{References}

Ashcroft N.W and Mermin N.D. (1976). Solid State Physics, Sauders College, Philadephia. Pp 345-368.

Brodie I. (1995). Work function of transition metals calculated from the Brodie's expression. Phys. Rev.B,51, 13660. http://dx.doi.org/10.1103/PhysRevB.51.13660

Halas, S. (2006). 100 years of work function. Materials science-Poland. Vol. 24 Number 4. Pp 951-968.

Halas, S. T.Durakiewicz. (1998). Work function of elements expressed in terms of the Fermi energy and the 
density of free electrons. J. phys. C: Condens. Matter. 10, 10815-10826. http://dx.doi.org/10.1088/0953-8984/10/48/005

Hudson J.B. (1992). Surface science: An introduction, Butterworth-Heinemann Publishers, New York. Pp 250-305.

Ibach, H. (1997). The role of surface stress in reconstruction, epitaxial growth and stabilization of mesoscopic structures. Surface science reports, 29, Pp. 193-263. http://dx.doi.org/10.1016/S0167-5729(97)00010-1

Jackson J.D. (1975). Classical electrodynamics, New York Wiley).Chapter 2, pg 179.

Kittel C. (1996). Introduction to Solid State Physics. 7th Edition (New York: Wiley). Chapter 10, pg 235-236.

Lang, N.D and Kohn. W. (1971). Theory of Metal Surface: Work function. Phys.Rev. B, Vol. 3, Number 4. Pp 1215-1223.

Lang N.D and Kohn.W. (1970). Theory of Metal Surface: Charge density and surface energy. Phys Rev. B, Vol. 1, Number 12 , Pp 4555-4567.

Mahan, G.D and Schaich, W.L. (1974), Comment of the theory of work function. Phys Rev. B, Volume 10, Number 6, Pp. 2647-2651. http://dx.doi.org/10.1103/PhysRevB.10.2647

Michaelson H.B. (1977). The work function of the elements and its periodicity. J. Appl. Phys, 48 (11), 4729-4733. http://dx.doi.org/10.1063/1.323539

Monnier R., Perdew, J.P. Langreth, D.C. and Wilkins, J.W. (1978). Change in self-consistenct-field theory of the work function. Phys. Rev. B, Vol. 18, Number 2. Pp. 656-666. http://dx.doi.org/10.1103/PhysRevB.18.656

Nishiyama $\mathrm{H}$ and Inoue Y. (2006). PEEM study of the work function changes in $\mathrm{Cu}, \mathrm{Au}$ and Pd metal surfaces with surface acoustic wave propagation. Surf. Sci., 600. 2644-2659. http://dx.doi.org/10.1016/j.susc.2006.03.047

Osiele, O.M. and Olubosede, O. (2007). Surface Energy of Elemental Metals using Stabilized Jellium Model. Nigerian Journal of Physics, 19 (1), 2007. pp. 9-16.

Perdew, J.P., Tran, H.Q. and Smith, E.D. (1990). Stabilized jellium: Structureless pseudopotential model for the cohesive and surface properties of metals. Phys. Rev. B., Volume 42, Number 18, Pp11627-11636. http://dx.doi.org/10.1103/PhysRevB.42.11627

Smith, J.R. (1969). Self-Consistence Many-Electron Theory of Electron Work functions and Surface potential Characteristics for selected metals. Phys. Rev., Volume181, Number 2. Pp 522-529. http://dx.doi.org/10.1103/PhysRev.181.522

Wigner E. and Bardeen, J. (1935). Theory of the work function of monovalent metals. Phy. Rev., Volume 48. Pp. 84- has been used in this work 87.

Yoshitake M and Yoshitake K. (2006). Determination of the transmission and correction of electron spectrometers, based on backscattering and elastic reflection of electrons. App. Surf. Sci., 144. 
Table 1. Input values and the results of calculations for the MPM model. SJM, $A b$-initio and Experimental values are taken from references Osiele, O.M. and Olubosede, O. (2007). P. 9-16, Ashcroft N.W and Mermin N.D (1976). P. 345-368. and Michaelson H.B, (1977) P. 4729-4733 respectively.

\begin{tabular}{|c|c|c|c|c|c|c|c|}
\hline Element & $\mathbf{Z}$ & $\begin{array}{l}\mathbf{r}_{\mathrm{s}} \\
\text { (a.u) }\end{array}$ & $\begin{array}{l}E_{F} \\
(e V)\end{array}$ & $\begin{array}{l}\text { Calculated } \\
\text { MPM (eV) }\end{array}$ & $\begin{array}{lr}\begin{array}{l}\text { Calculated } \\
\text { (eV) }\end{array} & \begin{array}{r}\text { SJM } \\
\text { Ref. }\end{array} \\
\text { (Osiele,O.M., } & \\
\text { et al. 2007) } & \\
\end{array}$ & $\begin{array}{l}\text { Ab-initio method } \\
\text { (eV) } \\
\text { Ref.(Ashcroft N.W et } \\
\text { al. 1976) }\end{array}$ & $\begin{array}{l}\text { Experimental } \\
\text { Value (eV) } \\
\text { Ref.(Michaelson } \\
\text { H.B, 1977) } \\
\end{array}$ \\
\hline $\mathrm{Li}$ & 1 & 3.26 & 4.74 & 2.92 & 2.92 & 3.33 & 2.9 \\
\hline $\mathrm{Na}$ & 1 & 3.99 & 3.24 & 2.61 & 2.64 & 2.76 & 2.75 \\
\hline $\mathrm{K}$ & 1 & 4.95 & 2.12 & 2.32 & 2.23 & 2.34 & 2.30 \\
\hline $\mathrm{Rb}$ & 1 & 5.31 & 1.85 & 2.25 & 2.13 & 2.22 & 2.16 \\
\hline Cs & 1 & 5.75 & 1.59 & 2.15 & 2.02 & 2.50 & 2.14 \\
\hline $\mathrm{Fr}$ & 1 & 6.12 & 1.50 & 2.0 & NA & NA & NA \\
\hline $\mathrm{Be}$ & 2 & 1.87 & 12.0 & 4.91 & 4.22 & 5.62 & 4.98 \\
\hline $\mathrm{Mg}$ & 2 & 2.65 & 7.10 & 3.79 & 3.34 & 3.86 & 3.66 \\
\hline $\mathrm{Ca}$ & 2 & 3.26 & 5.20 & 2.79 & 2.91 & 2.86 & 2.87 \\
\hline $\mathrm{Sr}$ & 2 & 3.55 & 4.49 & 2.64 & 2.74 & 2.42 & 2.59 \\
\hline $\mathrm{Ba}$ & 2 & 3.73 & 3.84 & 2.65 & 2.70 & 2.23 & 2.7 \\
\hline $\mathrm{Ra}$ & 2 & 3.92 & 3.00 & 2.78 & NA & NA & NA \\
\hline $\mathrm{Se}$ & 2 & 3.72 & 7.54 & 3.52 & 2.88 & 3.74 & 3.5 \\
\hline $\mathrm{Y}$ & 2 & 2.99 & 6.88 & 3.21 & 3.39 & 3.38 & 3.1 \\
\hline $\mathrm{La}$ & 3 & 2.89 & 6.10 & 3.57 & NA & NA & NA \\
\hline $\mathrm{Ac}$ & 3 & 2.89 & 6.10 & 3.58 & NA & NA & NA \\
\hline $\mathrm{Ti}$ & 3 & 2.24 & 8.84 & 4.28 & 4.16 & 4.59 & 4.33 \\
\hline $\mathrm{Zr}$ & 3 & 2.33 & 8.50 & 4.18 & 3.90 & 4.15 & 4.07 \\
\hline Hf & 3 & 2.43 & 8.69 & 3.89 & NA & NA & 3.9 \\
\hline $\mathrm{V}$ & 3 & 2.09 & 11.09 & 4.32 & 4.63 & 5.2 & 4.3 \\
\hline $\mathrm{Nb}$ & 3 & 2.13 & 10.82 & 4.25 & 3.88 & 4.63 & 4.3 \\
\hline $\mathrm{Ta}$ & 3 & 2.13 & 10.19 & 4.38 & 4.39 & 5.08 & 4.25 \\
\hline $\mathrm{Cr}$ & 3 & 1.98 & 11.95 & 4.50 & 4.25 & NA & 4.50 \\
\hline Mo & 3 & 2.03 & 11.36 & 4.52 & 4.28 & 5.34 & 4.60 \\
\hline $\mathrm{W}$ & 3 & 2.04 & 11.47 & 4.40 & NA & NA & 4.55 \\
\hline $\mathrm{Mn}$ & 3 & 2.01 & 12.20 & 4.37 & NA & NA & 4.10 \\
\hline Tc & 3 & 1.97 & 10.90 & 4.76 & NA & NA & NA \\
\hline $\mathrm{Re}$ & 3 & 2.01 & 10.90 & 4.62 & NA & NA & 4.72 \\
\hline $\mathrm{Fe}$ & 3 & 1.96 & 11.81 & 4.60 & 4.25 & 5.54 & 4.50 \\
\hline $\mathrm{Ru}$ & 3 & 1.96 & 10.82 & 4.81 & 4.15 & NA & 4.71 \\
\hline Os & 3 & 1.97 & 11.06 & 4.72 & NA & NA & 4.83 \\
\hline Co & 3 & 1.93 & 10.52 & 5.00 & NA & NA & 5.00 \\
\hline $\mathrm{Rh}$ & 3 & 2.07 & 9.26 & 4.80 & 4.12 & NA & 4.98 \\
\hline Ir & 4 & 1.87 & 10.26 & 5.31 & NA & NA & 5.27 \\
\hline $\mathrm{Ni}$ & 3 & 1.92 & 9.66 & 5.25 & 3.96 & NA & 5.25 \\
\hline $\mathrm{Pd}$ & 3 & 2.12 & 7.69 & 5.08 & 3.71 & NA & 5.12 \\
\hline $\mathrm{Pt}$ & 4 & 1.91 & 8.79 & 5.56 & 4.05 & NA & 5.65 \\
\hline $\mathrm{Cu}$ & 2 & 2.12 & 9.03 & 4.69 & 3.90 & NA & 4.65 \\
\hline $\mathrm{Ag}$ & 2 & 2.39 & 7.48 & 4.31 & 3.16 & NA & 4.26 \\
\hline $\mathrm{Au}$ & 3 & 2.22 & 7.25 & 4.88 & 3.59 & NA & 5.1 \\
\hline $\mathrm{Zn}$ & 2 & 2.30 & 8.65 & 4.24 & NA & NA & 4.33 \\
\hline $\mathrm{Cd}$ & 2 & 2.59 & 6.45 & 4.10 & 3.40 & NA & 4.22 \\
\hline $\mathrm{Hg}$ & 3 & 2.51 & 5.66 & 4.59 & NA & NA & 4.49 \\
\hline B & 2 & 1.84 & 15.40 & 4.44 & NA & NA & 4.45 \\
\hline $\mathrm{Al}$ & 3 & 2.07 & 11.30 & 4.34 & 3.96 & NA & 4.28 \\
\hline $\mathrm{Ga}$ & 3 & 2.19 & 10.40 & 4.16 & NA & NA & 4.2 \\
\hline In & 3 & 2.41 & 8.60 & 3.96 & NA & NA & 4.12 \\
\hline $\mathrm{Tl}$ & 3 & 2.49 & 6.00 & 3.88 & 3.51 & NA & 3.84 \\
\hline $\mathrm{C}$ & 2 & 1.93 & 10.50 & 5.0 & NA & NA & 5.0 \\
\hline $\mathrm{Si}$ & 4 & 2.00 & 12.50 & 4.34 & NA & NA & 4.85 \\
\hline $\mathrm{Ge}$ & 4 & 2.09 & 13.00 & 3.98 & NA & NA & 5.0 \\
\hline Sn & 4 & 2.22 & 10.20 & 4.12 & NA & NA & 4.42 \\
\hline $\mathrm{Pb}$ & 4 & 2.30 & 2.30 & 9.50 & 4.03 & 3.16 & 4.25 \\
\hline As & 5 & 1.91 & 11.90 & 4.77 & NA & NA & 5.11 \\
\hline $\mathrm{Sb}$ & 5 & 2.14 & 10.90 & 4.21 & NA & NA & 4.55 \\
\hline $\mathrm{Bi}$ & 5 & 2.25 & 9.90 & 4.09 & NA & NA & 4.22 \\
\hline $\mathrm{Se}$ & 6 & 1.94 & 7.50 & 5.87 & NA & NA & 5.9 \\
\hline $\mathrm{Te}$ & 6 & 2.12 & 8.00 & 4.98 & NA & NA & 4.95 \\
\hline Po & 6 & 2.20 & 7.00 & 5.03 & NA & NA & NA \\
\hline
\end{tabular}

Note: NA means not available 


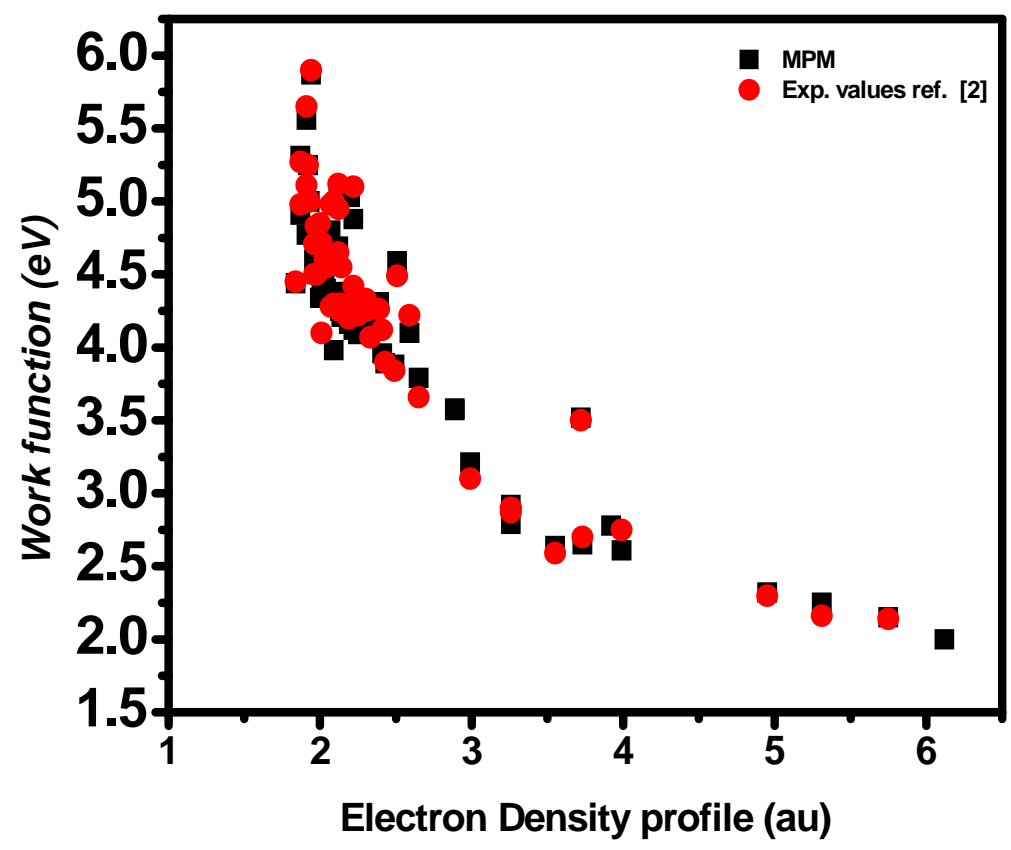

Figure 1. Comparison of MPM and experimental Values with electron density parameter

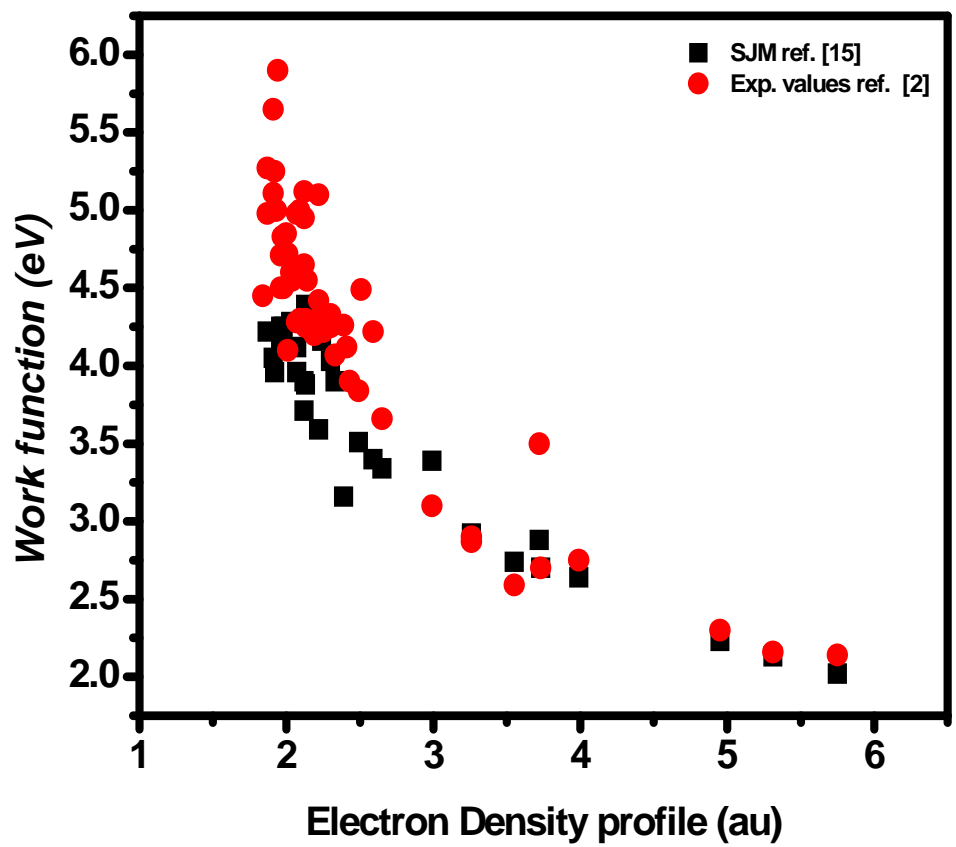

Figure 2. Comparison of SJM and experimental Values with electron density parameter 


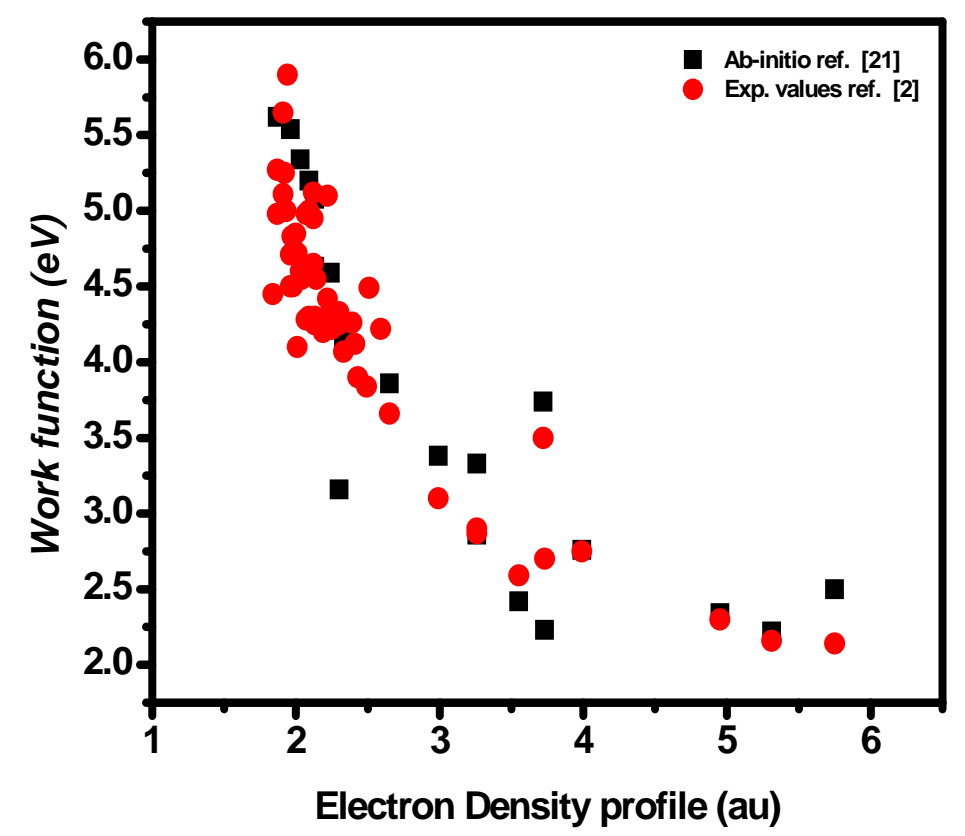

Figure 3. Comparison of Ab-initio and experimental Values with electron density parameter 